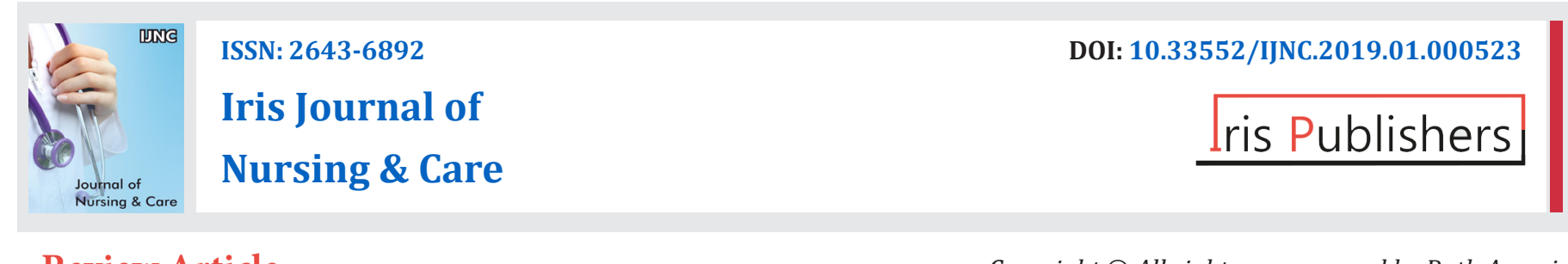

Review Article

Copyright (C) All rights are reserved by Ruth Azami

\title{
The Relationship Between Suicide and Quality Communication: A Literature Review
}

\author{
Ruth Azami* \\ Washburn University, USA
}

*Corresponding author: Ruth Azami, Washburn University, USA.

Received Date: May 05, 2019

Published Date: May 28, 2019

\section{Literature Review}

Suicide is the $10^{\text {th }}$ leading cause of death in the United States, which was 42,773 suicides in 2017 Nichols [1]. Female nurses are 4 times more likely to commit suicide than females in other careers Brennan [2]. In $82 \%$ of nurses surveyed, they reported a high risk for work- related stress Parkash [3]. Nurses work long hours and have little control of duties with high workloads and demands, which can cause stress and burnout.

Nurses are at risk for job stressors that can lead to mental health concerns. Nurse managers need to participate in the exchange of information and feelings to develop an understanding between one another Parkash [3]. The need for a healthy work environment is essential to the survival of medical professionals. Without quality communication among nurses and their managers, the suicide rate of nurses will remain high Thew [4].

Increased stress can increase the risk of suicide and emotional pain Davidson, Mendis, Stuck, DeMichele, \& Zisook [5]. When a health professional disengages and faces burnout at work there is an increased risk for self-harm Parkash [3]. Healthcare professionals experience high expectations and pressure at work while trying to maintain high quality care and productivity Parkash [3].

A study of 10,000 suicide cases from 2001-2012 was analyzed Brennan [2]. Healthcare professionals accounted for $3.8 \%$ of those deaths Brennan [2]. Approximately 9.6\% of nurses will experience an episode of major depression Thew [4]. Depression is a main contributory factor related to suicide Davidson et al. Nurse managers' role should include suicide prevention. There is a lack of education for nurse managers to prevent suicide Brennan [2]. Action needs to be taken to reduce the high rate of healthcare professionals' deaths.

There are several factors that increase the risk of suicide. According to the Centers for Disease Control (CDC, 2018), risks for increased risk of suicide are a family history of suicide, previous suicide attempt, history of mental health disorders, alcohol abuse, drug abuse, feeling of hopelessness, and feeling of isolation. According to the Centers for Disease Control (CDC, 2018), protective factors to decrease suicide are clinical treatment for mental and physical disorders, treatment for substance and alcohol abuse, and support by community and family. By communicating concern for an individual can promote treatment and quality communication to decrease the risk for death by suicide.

Depression and other personality disorders increase the risk for suicide Braquehais [6]. Providers encounter many patients with mental health concerns and need to know how to provide safe and quality care to prevent suicide. Learning how to use the theory of planned behavior promotes successful use of emotional pain communication, which is essential to intervene in suicidal behaviors and actions.

It can be challenging to communicate. Honest communication brings people together and bad communication leads to stress and errors Sherman [7]. This reinforces the need for quality communication in healthcare. Quality communication is a connection between two individuals, which requires listening, understanding and not being judgmental Davidson et al.

Qualities of good communication are being free from distractions, maintaining eye contact, being supportive and expressing a non-judgmental attitude. Quality communication is a two-way process of reaching a mutual understanding. The participants exchange information and feelings where they can develop a shared meaning Davidson et al. [5]. When a nurse manager has high quality communication techniques with staff nurses and co-workers, there can be a decreased stress level Davidson et al. [5].

Nurses feel cared for when leaders recognize them as a whole person Davidson et al. Nurses need to speak more directly to 
one another on issues that personally and professionally matter Davidson et al. Nurses and managers need to take time to ask themselves and one another if they are mentally and physically okay. Collaboration is helpful in promoting a positive work environment.

Nurses are trained to help others and tend to neglect their own mental and physical health needs Davidson et al. This reinforces the need to eliminate or decrease the stressors that increase the risk of nurse suicide. Communication can open doors for individuals who are suffering emotionally. A literature review was conducted to answer the question, do female nurses who have quality communication with their managers, have similar suicide rates, compared to female nurses who do not have quality communication with their nurse managers?

\section{Communication Research Literature Review}

Cochrane and CINAHL databases were selected to search for studies related to communication and suicide. The search was limited to select articles from 2008-2018. The studies were reviewed and selected based on effects related to communication and suicide behaviors (Table 1). The first research study reviewed examined message content to promote suicide intervention Aldrich \& Cerel [8]. This study reviewed the literature on suicide and the theory of planned behavior (TPB). The research discussed how the theory of planned behavior communication can decrease the risk of suicide Aldrich \& Cerel [8]. Research related to suicide, suicide behaviors and the TPB was collected on the internet and databases Aldrich \& Cerel [8].

Table 1: Review of Literature Studies of Communication and Decreased Risk of Suicide.

\begin{tabular}{|c|c|c|c|c|c|}
\hline Study \& Purpose & $\begin{array}{c}\text { Design \& Level of } \\
\text { Evidence }\end{array}$ & Sample \& Setting & Findings & Limitations & Implications for Practice \\
\hline $\begin{array}{l}\text { Aldrich \& Cerel [8] } \\
\text { Examine message } \\
\text { content to promote } \\
\text { suicide intervention. }\end{array}$ & $\begin{array}{l}\text { Review of literature } \\
\text { on suicide \& TPB \& } \\
\text { health behaviors } \\
\text { Discuss how TPB } \\
\text { communication can } \\
\text { prevent suicide } \\
\text { Level V }\end{array}$ & $\begin{array}{l}\text { Research on the in- } \\
\text { ternet \& databases } \\
\text { on suicide \& suicide } \\
\text { behaviors \&TPB } \\
\text { Lexington, KY }\end{array}$ & $\begin{array}{l}\text { TPB will increase pro- } \\
\text { viders understanding of } \\
\text { patient's emotional pain } \\
\text { TPB trained health care } \\
\text { workers can intervene } \\
\text { when working with } \\
\text { suicidal individuals or } \\
\text { situations }\end{array}$ & $\begin{array}{l}\text { Lack of formative } \\
\text { research } \\
\text { Study was limited to } \\
\text { literature review } \\
\text { TPB in used inconsis- } \\
\text { tently across studies } \\
\text { Publication bias }\end{array}$ & $\begin{array}{l}\text { Teaching \& using the TPB } \\
\text { model in practice can } \\
\text { reduce the risk of suicide } \\
\text { Medical professional need } \\
\text { to be trained Theory of } \\
\text { planned behavior to de- } \\
\text { crease suicidal behaviors }\end{array}$ \\
\hline $\begin{array}{l}\text { Dunkley et al. [10] } \\
\text { Explore factors that } \\
\text { impede and promote } \\
\text { pain communication. } \\
\text { Identify barriers } \\
\text { \& facilitators in } \\
\text { communication to } \\
\text { improve clinicians' } \\
\text { ability to intervene } \\
\text { suicidal behaviors. }\end{array}$ & $\begin{array}{l}\text { Individualized } \\
\text { \& focused group } \\
\text { interviews } \\
\text { Level VII }\end{array}$ & $\begin{array}{c}\text { In the United } \\
\text { Kingdom } \\
9 \text { female patient's } \\
\text { participants, aged } \\
27-58 \text { with more } \\
\text { than one admission } \\
\text { to hospital due to } \\
\text { suicidal actions } \\
26 \text { female mental } \\
\text { health staff }\end{array}$ & $\begin{array}{l}\text { Unsuccessful communica- } \\
\text { tion can deter communi- } \\
\text { cation between provider } \\
\text { and patient } \\
\text { Emotional pain communi- } \\
\text { cation is complex } \\
\text { Training staff about } \\
\text { emotional training can in- } \\
\text { crease the communication } \\
\text { quality with patients }\end{array}$ & $\begin{array}{l}\text { Female participants } \\
\text { only } \\
\text { No male participants } \\
\text { Reducing emotional } \\
\text { pain may be different } \\
\text { in men than women }\end{array}$ & $\begin{array}{l}\text { Co-bearing \& empathizing } \\
\text { with patients can decrease } \\
\text { emotional pain, which } \\
\text { allows for communica- } \\
\text { tion \& suicidal behavior } \\
\text { treatment. } \\
\text { Medical professionals need } \\
\text { to learn and understand } \\
\text { emotional behaviors to } \\
\text { prevent/decrease suicide }\end{array}$ \\
\hline
\end{tabular}

Note: $\mathrm{TPB}=$ theory of planned behavior

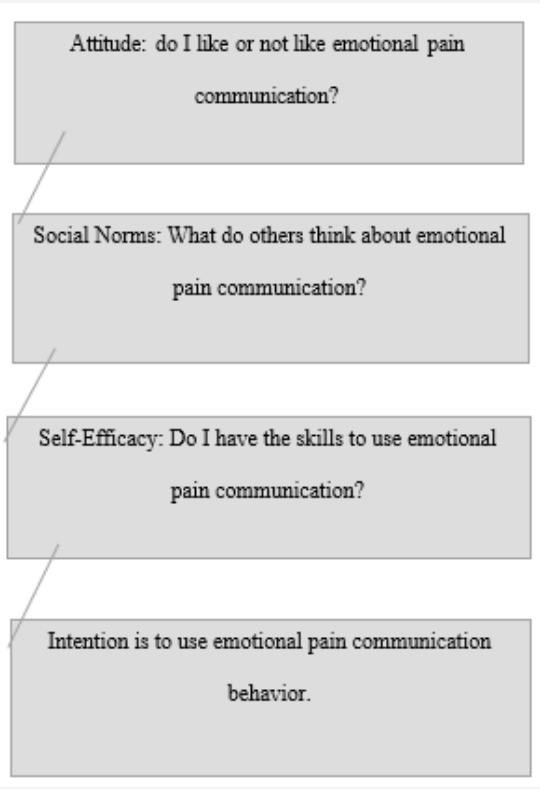

Figure 1: Appendix Theory of Planned Behavior Hackman \& Knowlden [9].
The theory of planned behavior (TPB) is an intrapersonal theory that is utilized to predict behavioral interventions and behaviors Hackman \& Knowlden. In the TPB, there are three constructs that enrich the behavioral intention, which are designed to be the strongest predictor of behavior Hackman \& Knowlden. The three constructs in the TPB are behavioral attitude beliefs, normative beliefs, and control beliefs Hackman \& Knowlden. Refer to the appendix for a more detailed description of the TPB [9] (Figure 1).

Findings suggest the TPB will increase providers understanding of patient's emotional pain Aldrich \& Cerel [8]. Findings also suggest the TPB trained health care workers can intervene when working with suicidal individuals or situations Aldrich \& Cerel [8]. This reinforces the need for mental health support and suicide awareness training for medical staff. Refer to table for detailed information regarding research. Implications for practice are to implement teaching and utilization of the TPB model and to teach warning signs of suicidal intentions to reduce the risk of suicide. Another implication for practice of the study is medical professionals need to be trained how to use the TPB to decrease 
suicidal behaviors Aldrich \& Cerel [8]. Theory of planned behavior in practice can benefit the provider and the patient by promoting safety and suicide reduction Aldrich \& Cerel [8].

The second research study reviewed sought to identify factors that impede and promote emotional pain communication Dunkley et al. Emotional communication is the ability to understand one's feelings, which promotes a successful conversation Dunkley et al. Being emotionally aware of one's feelings improves the quality of communication. Emotional pain communication is between those at risk for suicide and mental health care providing clinicians' ability to intervene in suicidal behaviors Dunkley et al. The study was a qualitative design composed of individualized and focus group interviews. The study took place in the United Kingdom. There were 9 female patient participants, aged 27-58 years with more than one hospital admission related to suicidal actions Dunkley et al. 2018. There were 26 female mental health staff in the study. Findings suggest unsuccessful communication can deter communication between provider and patient. Another finding suggested due to the complexity of emotional pain communication; training staff can increase the quality of emotional pain communication with patients Dunkley et al. 2018.

Limitation of this study was lack of male participants and publication bias. Implications for practice include co-bearing and empathizing with patients can decrease emotional pain, which allows for communication and suicidal behavior treatment Dunkley et al. 2018. Another implication for practice is medical professionals need to learn and understand emotional and suicidal behaviors to prevent and decrease suicide rates Dunkley et al. [10].

Suicide and depression are a worldwide concern. According to the Anxiety and Depression Association of America (ADAA, 2018), approximately $75 \%$ of individuals with mental health disorders are not treated with 1 million individuals committing suicide yearly [11]. This reinforces a strong need for the TPB education among providers to decrease the risk of suicide. Medical providers can save lives with increased knowledge and understanding of patient's emotional pain Aldrich \& Cerel 2009.

\section{Evidence Strength Levels}

The research articles were chosen within the last 10 years from academic journals. According to Polit \& Beck [12] level of evidence, one of the resources that was selected was a literature review with a level $V$ and the other resource was individualized and focus group interviews with a level VII classification. The resources utilized carried good quality level of evidence based on their classification. The studies recommended that by training staff in emotional pain communication can increase the quality of communication and can decrease the risk of suicide. Additional research needs to be done due to limited research related to communication and suicide.

\section{Recommendations}

Managers need to be trained in emotional pain communication and support their staff to decrease suicide among nurses Aldrich \&
Cerel 2009. Leadership needs to be supportive and avoid stigmas related to mental illness to prevent nurses from avoiding their mental health issues Centers for Disease Control [13]. Managers acknowledging that a staff member has emotional pain concerns can decrease the risk of nurse suicide Aldrich \& Cerel 2009.

The theory of planned behavior can intervene in suicide behaviors and actions by understanding patient's emotional pain Aldrich \& Cerel. Emotional pain is a harsh mental activity that is undesirable and possibly damaging Aldrich \& Cerel. Emotional pain can stem from a death, trauma, divorce, job loss and/or elevated stress levels. Emotional pain communication occurs when individuals engage in a conversation and one of the individuals is experiencing emotional pain. Emotional pain communication is complex and challenging.

Unsuccessful communication can damage communication between two individuals. Training medical staff emotional communication skills can increase communication quality Dunkley et al.. Theory of planned behavior can help managers learn to communicate with staff that is experiencing emotional pain. Empathy and sharing of feelings can decrease emotional pain, which allows from quality communication and suicidal behavior intervention and treatment Aldrich \& Cerel.

During the search for research it was very challenging to find research for the topic. CINHAL and Cochrane database were to locate research related to communication and suicide reduction. The Stetler model of evidenced based practice was used to determine the possibility of applying the TPB emotional pain communication to decrease suicide Melnyk \& Fineout Overholt [14]. The Stetler model established that emotional pain communication needs to be practiced among medical staff. The risk of not implementing emotional pain communication may lead to increased risk of medical staff having poor communication. The benefits of implementing emotional pain communication can improve communication quality and intervene in suicidal behaviors.

To implement emotional pain communication medical staff, need to be ready to receive education. Education for emotional pain communication will occur in a lunch and learn. The education for emotional pain communication will be an annual mandatory requirement for all medical staff.

In the education lunch and learn, staff will learn about the TPB. Medical staff will also practice using emotional pain communication with one another. Skits will be done in front of the lunch and learn room, so all participants can access response to emotional pain communication experience. Once education is completed all medical staff will apply emotional pain communication in practice. In six months, there will be a reevaluation of the implementation of emotional pain communication and adjustments will be made according to results. Reeducation on emotional pain communication will be given during new medical staff orientation and annually for all medical staff. 


\section{Conflict of interest}

No conflict of interest

\section{Acknowledgement}

None.

\section{References}

1. Nichols H (2017) Top 10 leading causes of death in the United States.

2. Brennan B (2016) Female doctors and nurses at least three times more likely to commit suicide: Study.

3. Parkash V (2018) American-Health-Care workers are committing suicide in unprecedented numbers.

4. Thew J (2018) Nurse suicide is real. Don't ignore.

5. Davidson J, Mendis J, Stuck A R, De Michele G, Zisook S (2018) Nurse suicide breaking the silence.

6. Braquehais M D, Eiroa-Orosa FJ, Holmes KM, Lusilla P, Bravo M, et al. (2016) Differences in physicians and nurses recent suicide attempts: An exploratory study. Arch Suicide Res 20(2): 273-279.
7. Sherman F (2018) What are the benefits of effective communication in the workplace.

8. Aldrich R S, Cerel J (2009) The development of effective message content for suicide intervention. Crisis 30(4): 174-179.

9. Hackman C L, Knowlden A P (2014) Theory of reasoned action and theory of planned behavior-based dietary interventions in adolescents and young adults: a systematic review. Adolesc Health Med Ther 5: 101114.

10. Dunkley C, Borthwick A, Bartlett R, Dunkley L, Palmer S, et al. (2018) Hearing the suicidal patient's emotional pain. Crisis Journal 39(4): 267274.

11. Anxiety \& Depression Association of America (2018) Anxiety and depression.

12. Polit D F, Beck C T (2017) Nursing research: Generating and assessing evidence for nursing practice. $\left(10^{\text {th }} \mathrm{edn}\right)$., Philadelphia, PA. Lippincott, USA.

13. Centers for Disease Control (2018) Suicide: risk and protective factors.

14. Melnyk B M, Fineout Overholt E (Eds.) (2015) Evidence-based practice in nursing \& healthcare: A guide to best practice ( $3^{\text {rd }}$ edn.). Philadelphia: Lippincott. USA. 